CpG ISLANDS

Sequences of at least $200 \mathrm{bp}$ with greater than $50 \%$ $\mathrm{G}+\mathrm{C}$ content and high $\mathrm{CpG}$ frequency.
${ }^{\star}$ Dipartimento di Biologia, Università di Roma 'Tor Vergata', Via della Ricerca Scientifica 1, Roma, Italy. \$stituto di Neuroscienze Sperimentali, Fondazione Santa Lucia, IRCCS, Via del Fosso di Fiorano 64, Roma, Italy.

${ }^{5}$ Departments of Psychology, Psychiatry and Cell and Structural Biology, and Beckman Institute, University of Illinois at Urbana-Champaign, 405 North Mathews Avenue, Urbana, Illinois 61801, USA. Correspondence to C.B. e-mail:claudia.bagni@ uniroma2.it

doi:10.1038/nrn1667

\title{
FROM mRNP TRAFFICKING TO SPINE DYSMORPHOGENESIS: THE ROOTS OF FRAGILE X SYNDROME
}

\author{
Claudia Bagni ${ }^{* *}$ and William T. Greenough ${ }^{\S}$
}

\begin{abstract}
The mental retardation protein FMRP is involved in the transport of mRNAs and their translation at synapses. Patients with fragile $X$ syndrome, in whom FMRP is absent or mutated, show deficits in learning and memory that might reflect impairments in the translational regulation of a subset of neuronal mRNAs. The study of FMRP provides important insights into the regulation and functions of local protein synthesis in the neuronal periphery, and increases our understanding of how these functions can produce specific effects at individual synapses.
\end{abstract}

Fragile X syndrome (FXS) is the most common cause of inherited mental retardation, and can be attributed to mutations in the FMR1 gene on the X chromosome. In most cases, fragile $\mathrm{X}$ syndrome is caused by the expansion of a polymorphic CGG repeat in the $5^{\prime}$ untranslated region (UTR) of the gene. Hypermethylation of the CGG repeats and the upstream CpG ISLANDS usually leads to transcriptional silencing of the gene ${ }^{1}$. A different phenotype, fragile $\mathrm{X}$ tremor ataxia syndrome (FXTAS), has recently been described in individuals who carry a 'premutation' in the FMR1 gene ${ }^{2}$. The clinical presentation includes either gait ataxia or intention tremor at onset, associated with a wide range of neurological symptoms and signs that include cognitive impairment, parkinsonism, peripheral neuropathy and autonomic dysfunction.

One of the key findings in patients with fragile $\mathrm{X}$ syndrome is that they have more dendritic spines than control subjects, and that the spines are longer and thinner. This morphology is also seen in the mouse model of the syndrome ${ }^{3-7}$. Spines are dynamic structures that can regulate many neurochemical events related to synaptic transmission and modulate synaptic efficacy ${ }^{8,9}$.

The development and modification of synaptic connections involves the integration of intrinsic cellular mechanisms and extrinsic information. Synaptic connections are dynamically regulated by many protein-protein interactions and protein modifications, such as phosphorylation and ubiquitylation. Another important aspect of synaptic regulation is protein synthesis and degradation - both locally, in dendrites and growth cones, and in the cell body ${ }^{10,11}$. Therefore, it is of interest to understand how the mRNAs that are required at synapses are selected from the pool of mRNAs in the nucleus, how they are transported along neuronal processes and how they are finally translated (apparently largely postsynaptically in spines and dendrites) in a regulated manner in response to presynaptic and other inputs.

Fragile X mental retardation protein (FMRP), which is encoded by the FMR1 gene, is one of a family of RNA-binding proteins known as heterogeneous nuclear ribonucleoproteins (hnRNPs) that are involved in many aspects of mRNA metabolism and biology. Recently, it has been shown that some of these are required for the export of mRNAs from the nucleus and their subcellular localization in the cytoplasm. These two processes seem to be connected ${ }^{12}$ : when RNA processing is complete, the RNA is exported through the nuclear pores. At this stage, some of the RNA-binding proteins are released, whereas others remain attached ${ }^{13}$. Splicing and other forms of nuclear processing can specify aspects of targeting. One example of an hnRNP that functions in this way is the zipcode binding protein 2 (ZBP2). 


\section{Box 1 | FMRP RNA-binding modules}

Fragile X mental retardation protein (FMRP) has two K homology (KH) domains, one RGG box (a cluster of arginine and glycine residues) and an amino (N) terminus that has a strong affinity for RNA. The KH module - an evolutionarily conserved sequence motif that was originally identified as three repeats in the human heterogeneous nuclear ribonucleoprotein (hnRNP) K protein $^{129,130}$ - is present in proteins from bacteria through to humans. $\mathrm{KH}$-containing domains bind preferentially to specific RNAs ${ }^{131,132}$, although they can also bind to DNA ${ }^{133,134}$. Specific RNA targets for this domain have not yet been isolated.

The RGG box is an RNA-binding domain consisting of Arg-Gly-Gly repeats. It is found in hnRNP proteins, nucleolar proteins involved in RNA metabolism and several viral proteins ${ }^{135-137}$. The RGG box is considered to have an accessory role in RNA binding that promotes the unfolding of RNA secondary structure. This role has been shown for RNA-binding proteins that are involved in ribosome biogenesis, such as nucleolin ${ }^{138,139}$, fibrillarin ${ }^{140}$, glycine arginine rich protein 1 (GAR1) in yeast ${ }^{141}$ and nuclear signal recognition protein 1 (NSR1) ${ }^{142}$. Moreover, in hnRNPA2, RGG repeats are crucial for the cellular localization of the protein ${ }^{143}$. Specific binding of FMRP to G-QUARTETS has been mapped to the RGG box ${ }^{79}$. The conformation of RNA targets and their mode of binding to RGG repeats are heterogenous ${ }^{84}$, which indicates that other cis-acting sequences in target mRNAs are also involved in their association with FMRP. The N-terminal domain of FMRP also binds to RNA ${ }^{63,77}$, but is not homologous to any known RNA-binding motif. However, homology has recently been shown with proteins belonging to the 'Royal family', including the tudor protein $\mathbf{s}^{144}$.

The RNA-binding motifs could also serve other roles. A particularly severe form of fragile $\mathrm{X}$ syndrome involves an asparagine for isoleucine missense mutation at amino acid position 304 in the second $\mathrm{KH}$ module of the fragile $\mathrm{X}$ mental retardation 1 gene $(F M R 1)^{36}$. The mutation alters the RNA-binding activity of FMRP ${ }^{132,145-147}$. The mutated FMRP cannot form homodimers ${ }^{28}$, inhibit the translation of mRNA in vitro or inhibit the formation of the initiation complex $80 \mathrm{~S}^{148,149}$, and shuttles more rapidly between the nucleus and the cytoplasm ${ }^{37}$.

G-QUARTET

Intramolecular, bimolecular or tetramolecular structures. Guanine is arranged in series to form a planar layer, which is cation dependent.

NONSENSE-MEDIATED DECAY (NMD). A mechanism by which cells recognize and degrade mRNAs that prematurely terminate translation.

\section{MESSENGER}

RIBONUCLEOPROTEIN (mRNP). An mRNA, associated with proteins, that is translationally inactive.

K HOMOLOGY DOMAIN (KH domain). A sequence motif that was originally identified as three repeats in the human hnRNP K protein and that is present in proteins from bacteria through to humans. The motif expands around a conserved VIGXXGXXI core (where $\mathrm{X}$ is any amino acid, with a preference for positive residues).
Although this is predominantly a nuclear protein, it shuttles and contributes to the cytoplasmic localization of $\beta$-actin mRNA in fibroblasts and neurons ${ }^{14}$.

The best characterized examples of hnRNPs that are involved in mRNA localization include hnRNPA2, which is required for localization of the myelin basic protein (MBP) mRNA in oligodendrocytes ${ }^{15,16}$, and the ZBP family, which also includes Vera (hnRNP1) in Xenopus laevis ${ }^{17}$ and ZBP1/2 in chickens ${ }^{18}$ and mammals ${ }^{19}$. These last examples were initially identified because they bind to a 54-nucleotide sequence (zipcode) in the $3^{\prime}$ UTR of the $\beta$-actin mRNA ${ }^{20}$. Another important hnRNP that influences the cytoplasmic fate of mRNA is the exon-junction complex, which is deposited onto each exon-exon junction by the premRNA splicing machinery in the nucleus ${ }^{21}$. Eukaryotic translation-initiation factor 4AIII (eIF4AIII) forms part of the exon-junction complex, and is involved in both the localization of oskar mRNA, which is responsible for the Drosophila melanogaster pole plasm, and NONSENSE-MEDIATED DECAY ${ }^{21-23}$. Further functions of hnRNP proteins include splice site selection during nuclear pre-mRNA splicing, regulation of translation efficiency, and regulation of mRNA stability and, therefore, abundance.

FMRP forms part of a large MESSENGER RIBONUCLEOPROTEIN (mRNP) complex that is involved in the transport and translation of mRNA in neurons (see below). The domain structure of FMRP — which includes two ribonucleoprotein к HOMOLOGY DOMAINs (KH domains) and a cluster of arginine and glycine residues (RGG BOX) that supports RNA binding - bears the hallmarks of a typical hnRNP protein (BOX 1) and is probably involved in many pathways that relate to RNA biogenesis and metabolism. In addition, there is evidence that the neuronal alterations associated with fragile $\mathrm{X}$ syndrome, such as abnormal spines ${ }^{3-7}$, can be ascribed to impairments in mechanisms that are involved in neural plasticity. Therefore, it is tempting to speculate that FMRP participates in mRNA transport to the synapse and/or in localized protein synthesis in dendrites. To understand its functions at the molecular level, it is important to characterize which mRNAs are targeted by FMRP, and which other proteins bind directly or indirectly to the protein, as their identities can reveal mechanisms that underlie the function of FMRP. It is also important to look at the sub-cellular distribution of 'cargo mRNAs' and proteins that bind to FMRP to understand where and how FMRP exerts its effects. FMR1 is one such cargo mRNA, and is translated at synapses in response to the activation of group I metabotropic glutamate receptors (mGluR1s) ${ }^{24,25}$, so FMRP might have functions other than transporting and activating or inhibiting the translation of the transported mRNA. In this review, we summarize recent progress that has been made in answering these questions and describe a possible role for FMRP in translational control. Finally, we discuss how the molecular functions of FMRP might lead to the defects in spine morphology that are seen in fragile X syndrome.

\section{Localization of FMRP}

FMRP in the nucleus. Although conventional methods do not usually show FMRP in the nucleus, it has been detected there using sensitive techniques. A small amount of FMRP immunoreactivity has been seen in the nucleus with both light and electron microscopy ${ }^{26-28}$, although the protein was detected using an antibody, 1C3, which also reacts slightly with the FMRP-homologous protein FXR1P29. FMRP can interact with a distinct set of nuclear proteins including nucleolin, the nuclear FMRP interacting protein (NUFIP), FXR1P and FXR2 $\mathrm{P}^{30,31}$. Interestingly, a particle that contains FMRP and the nuclear/cytoplasmic Y-box-binding protein 1 (YB1, also called p50) has also been identified $^{32}$. YB1/p50 participates in several steps of mRNA biogenesis, including mRNA transcription, processing and transport from the nucleus, and is also involved in the regulation of mRNA localization, translation and stability in the cytoplasm ${ }^{33,34}$.

In the nucleus, one role of FMRP could be to associate with mRNAs and escort them out of the nucleus (FIG. 1). This hypothesis is supported by the fact that FMRP contains both a functional nuclear localization signal (NLS) and a nuclear export signal (NES), which indicates that it can shuttle between the nucleus and the cytoplasm ${ }^{27}$. However, not all isoforms shuttle between the nucleus and cytoplasm - the alternatively spliced exon 14 of FMRP encodes the NES, and this FMRP isoform remains in the nucleus and cannot be exported to 


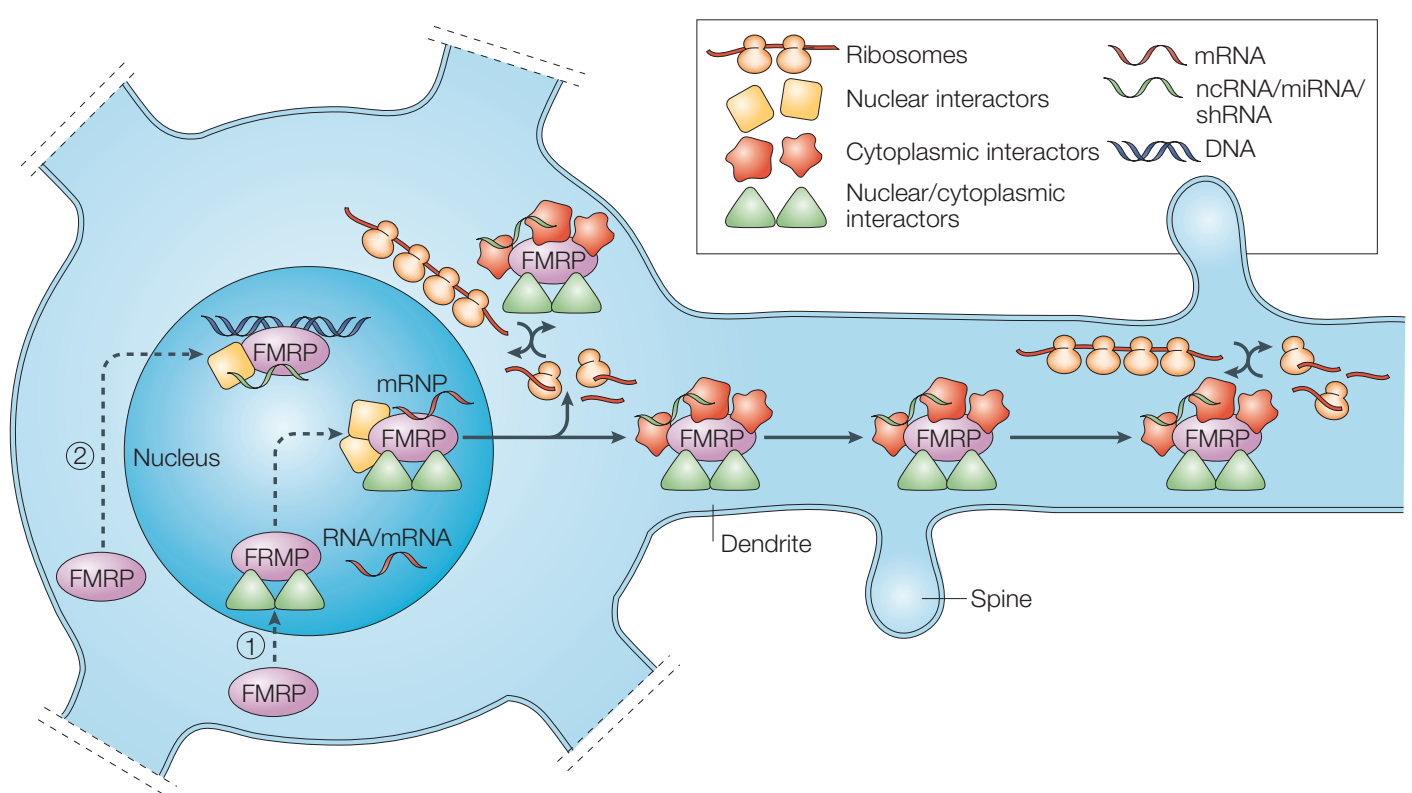

Figure 1 | Speculative model for FMRP shuttling between the nucleus and cytoplasm. Fragile X mental retardation protein (FMRP) enters the nucleus and could function through two possible mechanisms. In the first (1), FMRP could interact with other proteins, with itself (for example, the FMRP-homologous proteins FXR1P and FXR2P), and with RNA/mRNA to form a ribonucleocomplex that is probably involved in mRNA export from the nucleus to the cytoplasm. Once in the cytoplasm, a 'core' complex, containing FMRP and some of its nuclear partners, would interact with cytoplasm-specific proteins (such as cytoplasmic FMRP-interacting protein 1 (CYFIP1), CYFIP2 and Staufen) and move along dendrites to the synapses, transporting RNA/mRNA and, later, regulating synaptic protein synthesis. In the second mechanism (2), FMRP could be involved in the nuclear RNA interference pathway that is associated with small, non-coding RNAs (short hairpin RNAs or shRNAs) and specific nuclear partners (that is, nucleolin and Y-box binding protein 1 (YB1)). miRNA, microRNA; ncRNA, non-coding RNA.

\section{RGG BOX}

A protein region that is rich in arginine and glycine residues, is positively charged and has a high affinity for RNA molecules.

CHROMATIN REMODELLING Epigenetic DNA modifications that silence genes at a transcriptional level without altering their structure. Alterations in chromatin remodelling cause various multi-system disorders and neoplasias.

microRNA

A non-coding RNA molecule of 21-24 nucleotides that inhibits mRNA expression.

SYNAPTONEUROSOMES Purified synapses containing the pre- and postsynaptic termini. The presynaptic compartment contains the synaptic vesicles and the postsynaptic compartment contains the translational machinery. the cytoplasm, as shown by the transfection of a cDNA that lacks exon 14 (REF. 35). A mutated FMRP that contains an asparagine for isoleucine substitution at amino acid position 304 in the second $\mathrm{KH}$ domain ${ }^{36}$ (see also below) shuttles more frequently between the nucleus and cytoplasm, which indicates either that many domains are involved in nuclear entrance and export ${ }^{37}$ or, more probably, that bound mRNA slows the transport/shuttling process or makes re-entry to the nucleus unlikely. Moreover, cells that have been treated with leptomycin B, which blocks mRNA export, partially retain FMRP in the nucleoplasm ${ }^{35}$. Further support for a putative nuclear 'shuttle' function comes from the finding that the FMRP carboxyl (C) terminus interacts with the Ran-binding protein RanBPM ${ }^{38,39}$. RanBPM was originally identified as a protein that interacts with Ran, which comes in two conformationally distinct states (RanGTP or RanGDP) and which governs the assembly and disassembly of cargo complexes for nuclear trafficking ${ }^{40}$. As it is involved in nuclear trafficking ${ }^{41}$, RanBPM might help FMRP to shuttle.

A second possible role for FMRP in the nucleus could be CHROMATIN REMODELLING (FIG. 1). In vitro, FMRP binds strongly to single-stranded DNA and, to a lesser extent, to double-stranded $\mathrm{DNA}^{42}$. In addition, human FMRP associates with non-coding RNAs ${ }^{43}$ and microRNAs $(\text { miRNAs })^{44}$. miRNAs regulate mRNA expression ${ }^{45}$ and participate in chromosome methylation ${ }^{46,47}$. Mammalian FMRP has been shown to interact with a mammalian Argonaute protein (eIF2C2) ${ }^{44}$ and the three components
(FMRP, Argonaute and miRNAs) have also been detected in the nucleus, where RNA interference (RNAi)-mediated pathways operate ${ }^{48}$. It is, therefore, tempting to suggest that FMRP could contribute to chromatin remodelling through the RNAi pathway in the nucleus. Although it is clear that FMRP interacts with non-coding $\mathrm{RNA}^{43,44}$, the sequences of the miRNAs that might associate with human FMRP and the nuclear functions of FMRP require further investigation.

FMRP in dendrites and mRNP transport. Gene expression in neurons also involves the transport of some mRNAs away from the cell body and local protein synthesis in dendrites. These two steps are required for establishing and maintaining synaptic plasticity ${ }^{11}$ and are widely thought to be involved in learning and memory.

Several lines of evidence suggest that FMRP has an active role in mRNA transport, although there is no direct evidence that it transports mRNA. FMRP and its mRNA are found in both the soma and dendritic processes, including dendritic spines ${ }^{49}$. In dendrites and spines, FMRP and FMR1 mRNA co-localize in granules, and the movement of these granules into dendrites is enhanced by neuronal activation through mGluRs ${ }^{49}$. The presence of FMRP along the length of the dendrites depends not on protein synthesis but on transport ${ }^{49}$. As FMR1 is translated in unstimulated SYNAPTONEUROSOMES ${ }^{43}$ as well as in response to mGluR 
stimulation $^{24}$, it is possible that FMR1 is translated only at the synapse and not during transport. In any case, both FMR1 and FMRP are transported in granules to locations throughout the dendrite, where translation of the accompanying mRNA, and possibly mRNA from other sources, is regulated by synaptic activation. In the absence of FMRP, mGluR activation does not trigger increased protein synthesis in synaptoneurosomes ${ }^{25}$.

Further support for the idea that FMRP has a role in transport involves the regulator of G-protein signalling 5 (RGS5) and dystroglycan-associated protein 1 (DAG1) mRNAs, both of which are confirmed FMRP cargoes. Their expression is much less extensive in the dendritic region of FMR1-knockout mice than in wild-type mice $e^{50}$, and this is not a general effect of the knockout, because only some of the cargo mRNAs show this pattern. Moreover, the presence of microtubule-associated protein 2 (MAP2), which, in this study, was not found to be a cargo mRNA, did not change in dendrites as previously reported ${ }^{51}$. So, only some of the mRNAs that bind FMRP seem to need it for transport into dendrites. It might be that more than one complex is involved in the transport/localization of some mRNAs.

In a recent paper, a large RNAase-sensitive granule, binding partner of kinesin, was characterized ${ }^{52}$. The authors used mass spectrometry to identify 42 proteins, and after stringent conditions they could still detect a 'core' composed of $\alpha$-calcium/calmodulin-dependent protein kinase II ( $\alpha$-CaMKII) and activity-regulated cytoskeletal-associated protein (ARC, also called ARG3.1) mRNAs, as well as the purine-rich single stranded DNA-binding proteins $\alpha$ and $\beta$ (PUR $\alpha$ and PUR $\beta$ ), Staufen, FMRP, FXR1P, FXR2P, elongation factor $1 \alpha(\mathrm{EF} 1 \alpha)$ and kinesin 5 (KIF5). Interestingly, the $\alpha$-CaMKII and ARC mRNAs were both found to be associated with FMRP in another study ${ }^{43}$. Collectively, these data strengthen the argument that there is at least one RNA-transporting complex that contains FMRP in the mouse brain.

Moreover, FMRP and ZBP1/insulin-like growth factor II mRNA-binding protein1 (IMP1), a protein that has a defined role in mRNA transport in fibroblasts and neurons, can recruit each other into RNP granules in $v i v o^{53}$. Finally, using D. melanogaster S2 cells, Ling et al..$^{54}$ make a case for the combined involvement of both kinesin heavy chain and dynein in the bidirectional transport of green fluorescent protein (GFP)-tagged FMRP-containing granules on microtubules. Although there is some evidence to indicate that a particular FMRP domain is involved in granule formation in PC12 cells ${ }^{55}$, the mechanism by which FMR1 mRNA is localized to synapses is unknown.

We believe that work towards the involvement of FRMP in mRNP transport will make a significant contribution to the future understanding of fragile $\mathrm{X}$ syndrome. There are some patients with fragile X syndrome who cannot be diagnosed using conventional methods because they do not have the expansion in the $5^{\prime}$ UTR as well as mutations in the coding region ${ }^{56}$. In these patients, it is possible that the delivery of FMRP and/or of FMR1 mRNA to synapses is disrupted by mutations that affect the localization process.

\section{Binding partners for FMRP}

Proteins that interact with FMRP. Although fragile X syndrome is a monogenic disease, other factors might involved in the same biochemical pathway as FMRP, which could explain why the severity of the syndrome varies between patients that lack the same protein. Using immunoprecipitation, two-hybrid screens or large mass spectrometry analysis, several groups have identified proteins that interact with FMRP. Many putative FMRP-interacting proteins have been isolated and characterized ${ }^{30,32,52,57-61}$, most of which interact with the amino (N)-terminal portion of FMRP ${ }^{59,62,63}$. The only protein that has so far been found to interact with the C terminus of FMRP is RanBPM ${ }^{39}$. A list of FMRP-interacting proteins can be found in TABLE 1. We have also listed homologues in other species, as this allows us to infer whether the function is evolutionarily conserved. In this review, we focus on FMRPinteracting proteins that might explain the fragile $\mathrm{X}$ phenotype.

First, FMRP can interact with itself, as the $\mathrm{N}$ terminus contains a homodimerization domain. It also interacts with the two FMRP-homologous proteins FXR1P and FXR2P, in both the nucleus and in the cytoplasm $^{57}$. A low level of FMRP expression has been detected in a human prenatal heart ${ }^{64}$, which might explain why patients with fragile $\mathrm{X}$ syndrome have cardiac abnormalities ${ }^{65}$. A recent study of FXR1knockout mice revealed that this gene is essential for heart development and function ${ }^{66}$. In the cytoplasm, FMRP also interacts with the cytoplasmic FMRPinteracting proteins 1 and 2 (CYFIP1 and CYFIP2), which are highly homologous to each other. CYFIP2 interacts with all members of the FXR family, whereas CYFIP1 is specific to FMRP. CYFIP1 and 2 are localized at synapses ${ }^{58}$ and CYFIP1 also interacts with the small GTPase Rac1 (REF. 67). The D. melanogaster homologue of FMRP, also known as DFXR, has been linked with the Rho-GTPase pathway and synapse formation $^{68}$.

The $82-k D a$ FMRP-interacting protein (82-FIP) seems to be found in both the nucleus and the cytoplasm. It shows no homology to proteins of known function or to any known functional domain and, like NUFIP1 and CYFIP1, interacts with FMRP but not with FXR1P or FXR2P. 82-FIP is found in most neurons, and its subcellular distribution is cell-cycle dependent in COS cells, which indicates that the composition of some FMRP-containing RNP complexes might be cell-cycle modulated ${ }^{69}$. Immunoprecipitation experiments identified two more putative nuclear FMRP-interacting proteins: nucleolin and YB1/p50 (REFS 30,32). Furthermore, immunoprecipitation of PUR $\alpha$ co-precipitated FMRP, Staufen and myosin VA, among others. The immunoprecipitation is sensitive to treatment with RNAase, which indicates that these proteins are part of an (m)RNP complex. PUR proteins and Staufen have been implicated in mRNA 


\begin{tabular}{|c|c|c|c|}
\hline FMRP interactor & Cellular localization & Similar genes in other organisms & Isolation method \\
\hline FXR1P & Nucleus and cytoplasm & $\begin{array}{l}\text { Human, mouse, rat, } X \text {. laevis, } \\
\text { zebrafish }\end{array}$ & Yeast two-hybrid system ${ }^{57}$ \\
\hline FXR2P & Nucleus and cytoplasm & $\begin{array}{l}\text { Human, mouse, rat, } X \text {. laevis, } \\
\text { zebrafish }\end{array}$ & Yeast two-hybrid system ${ }^{57}$ \\
\hline NUFIP1 & Nucleus & Human, mouse, rat, D. melanogaster & Yeast two-hybrid system ${ }^{151}$ \\
\hline CYFIP1 & Cytoplasm & $\begin{array}{l}\text { Human, mouse, rat, } X \text {. laevis, } \\
\text { zebrafish, D. melanogaster, C. elegans }\end{array}$ & Yeast two-hybrid system 58 \\
\hline CYFIP2 & Cytoplasm & Human, mouse, rat, $X$. laevis & $\begin{array}{l}\text { High sequence homology } \\
\text { with CYFIP1 (REF. 58) }\end{array}$ \\
\hline 82-FIP & Nucleus and cytoplasm & Human, mouse, $X$. laevis & Yeast two-hybrid system ${ }^{69}$ \\
\hline Nucleolin & Nucleus & $\begin{array}{l}\text { Human, mouse, rat, G. gallus, } \\
\text { X. laevis, D. melanogaster, C. elegans }\end{array}$ & Co-immunoprecipitation ${ }^{30}$ \\
\hline YB1/p50 & Nucleus & $\begin{array}{l}\text { Human, mouse, rat, } X \text {. laevis, } \\
\text { zebrafish, } D \text {. melanogaster, C. elegans }\end{array}$ & Co-immunoprecipitation ${ }^{32}$ \\
\hline Staufen & Cytoplasm & $\begin{array}{l}\text { Human, mouse, rat, } X \text {. laevis, } \\
\text { zebrafish, D. melanogaster, } \\
\text { C. elegans }\end{array}$ & $\begin{array}{l}\text { Co-immunoprecipitation }{ }^{60} \text {, } \\
\text { TAP-technology }{ }^{61,152}\end{array}$ \\
\hline PUR $\alpha$ & Cytoplasm & $\begin{array}{l}\text { Human, mouse, rat, D. melanogaster, } \\
\text { C. elegans }\end{array}$ & Co-immunoprecipitation ${ }^{60}$ \\
\hline PUR $\beta$ & Cytoplasm & $\begin{array}{l}\text { Human, mouse, } X \text {. laevis, zebrafish, } \\
\text { D. melanogaster }\end{array}$ & Co-immunoprecipitation ${ }^{52}$ \\
\hline Myosin VA & Cytoplasm & $\begin{array}{l}\text { Human, mouse, rat, } D \text {. melanogaster, } \\
\text { C. elegans, } X \text {. laevis }\end{array}$ & Co-immunoprecipitation ${ }^{60}$ \\
\hline RanBPM & Nucleus and cytoplasm & $\begin{array}{l}\text { Human, mouse, rat, } X . \text { laevis, } \\
\text { D. melanogaster }\end{array}$ & Yeast two-hybrid system ${ }^{39}$ \\
\hline elF2C2/AGO1 & Nucleus and cytoplasm & Human, mouse, rat, D. melanogaster & Co-immunoprecipitation ${ }^{44,87}$ \\
\hline Dicer & Nucleus and cytoplasm & $\begin{array}{l}\text { Human, mouse, rat, } X \text {. laevis, } \\
\text { zebrafish, } D \text {. melanogaster }\end{array}$ & Co-immunoprecipitation ${ }^{88}$ \\
\hline PABP1 & Cytoplasm & $\begin{array}{l}\text { Human, mouse, rat, } X \text {. laevis, } \\
\text { zebrafish, D. melanogaster, C. elegans }\end{array}$ & $\begin{array}{l}\text { TAP-technology }{ }^{61,152} \\
\text { immunoprecipitation }^{52}\end{array}$ \\
\hline $\begin{array}{l}\text { Kinesin heavy } \\
\text { chain }\end{array}$ & Cytoplasm & $\begin{array}{l}\text { Human, mouse, rat, } X . \text { laevis, } \\
\text { D. melanogaster, C. elegans }\end{array}$ & $\begin{array}{l}\text { TAP-technology }{ }^{60,152} \\
\text { immunoprecipitation } \\
52\end{array}$ \\
\hline $\begin{array}{l}\text { Dynein } \\
\text { intermediate chain }\end{array}$ & Cytoplasm & Human, mouse, rat, D. melanogaster & TAP-technology ${ }^{61,152}$ \\
\hline
\end{tabular}

C. elegans, Caenorhabditis elegans; CYFIP1/2, cytoplasmic fragile X mental retardation protein (FMRP)-interacting protein 1/2; D. melanogaster, Drosophila melanogaster; elF2C2, eukaryotic translation-initiation factor 2C, 2 (also known as Argonaute 1 (AGO1)); FMRP, fragile $x$ mental retardation protein; FXR1P/2P, fragile X mental retardation 1/2; G. gallus, Gallus gallus; NUFIP1, nuclear FMRPinteracting protein 1; PABP1, poly(A)-binding protein 1; PUR $\alpha / \beta$, purine-rich single stranded DNA-binding proteins $\alpha$ and $\beta$; RanBPM, Ran-binding protein; TAP-technology, tandem affinity purification technology; X. laevis, Xenopus laevis; YB1, Y-box-binding protein 1; 82-FIP, 82-kDa FMRP-interacting protein.

transport and the regulation of translation ${ }^{70-72}$ through a possible interaction with a kinesin motor $^{73}$, and it is, therefore, interesting to find them in the same mRNP complex as FMRP. Moreover, the complex also contains the small dendritic non-coding brain cytoplasmic RNA 1 (BC1 $)^{60,74}$, which anneals to complementary regions of some mRNA targets ${ }^{43}$. Interestingly, both kinesin 1 and dynein seem to be involved in FMRP and Fmr1 transport in D. melanogaster ${ }^{4}$.

The FMR1 gene has attracted substantial attention because of its direct correlation with fragile X syndrome, but none of the proteins that interact with FMRP has yet been associated with a disease, except for myosin VA, which is associated with Griscelli syndrome, an autosomal recessive disorder that is characterized by partial albinism with variable immuno- deficiency ${ }^{75}$. Moreover, none of the genes that encode FMRP-interacting proteins has, so far, been linked to hereditary mental retardation.

$m R N A$ targets of FMRP. FMRP and the related proteins FXR1P and FXR2P share the same domain structure (BOX 1) and show more than $60 \%$ amino acid identity to each other ${ }^{57,76}$. The domain structure includes two KH domains, an RGG box and an RNA-binding domain in the $\mathrm{N}$-terminal region of the protein ${ }^{63,77}$ (F. Zalfa and C.B., unpublished observations). Consistent with this domain structure, FMRP binds to RNA homopolymers and to a subset of transcripts that are found in the brain $^{42,43,50,77-80}$. The learning and memory difficulties that are found in patients with fragile $\mathrm{X}$ syndrome and in the mouse model of the syndrome are probably due 


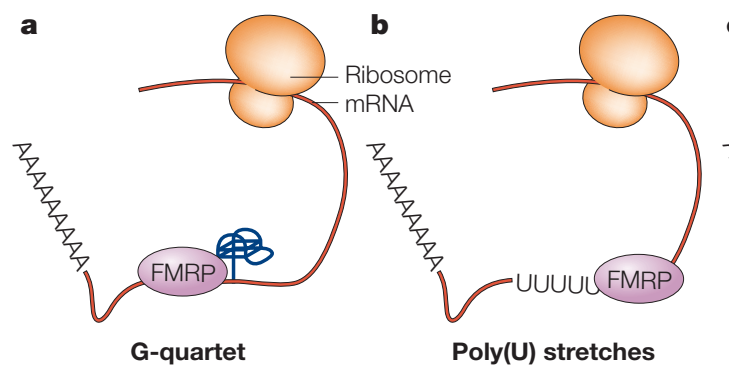

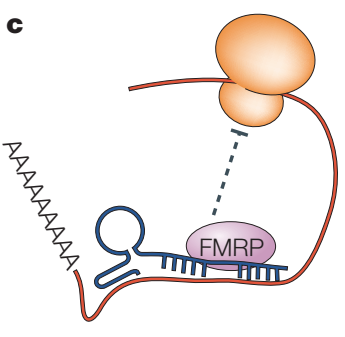

BC1

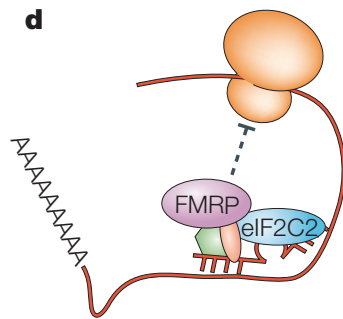

miRNA

Figure 2 | FMRP recognizes different RNA sequences. Fragile X mental retardation protein (FMRP) binds different neuronal mRNAs. Four mechanisms of target recognition have been characterized. FMRP could recognize a G-quartet structure (a) or a poly $(U)$ stretch (b) in the mRNA. Alternatively, FMRP could bind indirectly to the mRNA through either the small non-coding RNA brain cytoplasmic RNA 1 (BC1) (c) or microRNAs (miRNAs) (d). elF2C2, eukaryotic translation initiation factor 2C, 2.

to alterations in the metabolism of mRNAs that are important for synaptic structure and function. As a result, several attempts have been made to characterize the mRNAs that are bound by FMRP in neurons.

In the first study ${ }^{78}$, the FMRP-RNP complex was immunoprecipitated and the mRNAs were screened with microarrays. More than 400 mRNAs were identified as being associated with FMRP in the mouse brain. In parallel studies, the same group compared the mRNA polysomal profile of LYMPHOBLAST CELLS from control subjects and patients with fragile $\mathrm{X}$ syndrome. This produced another set of $251 \mathrm{mRNAs}$ that showed variations in their distribution on a POLYSOME gradient, which reflects a difference in the translational status of these mRNAs. However, the cytoplasmic abundance of these mRNAs remained unchanged. The two sets have 14 mRNAs in common. These mRNAs encode proteins that are important for neuronal function, synaptic plasticity and neuronal maturation, including the mRNA for MAP1B, which is also translationally dysregulated in $D$. melanogaster mutants for the homologous FMR gene ${ }^{81}$.

Using in vitro selection of random RNA sequences (SELEX, systemic evolution of ligands by exponential enrichment), Darnell and collaborators ${ }^{79}$ showed that FMRP binds a class of RNAs with G-quartet motifs (FIG. 2a). Thirty-one candidate mRNAs containing this motif were identified in the database. Twelve of these were assayed for FMRP binding and six bound strongly to FMRP. All six are associated with synaptic function, and they include MAP1B mRNA. They also show altered translational efficiency in fragile $\mathrm{X}$ cell lines. FMR1 mRNA also contains a G-quartet structure ${ }^{82}$. The G-quartet is apparently not the only RNA motif that is recognized by FMRP - as might be expected from its many mRNA-binding domains, FMRP can also bind to mRNAs that contain U-rich stretches ${ }^{80}$ (FIG. 2b).

Another study that used immunocytochemistry, antibody-positioned RNA amplification (APRA) and follow-up direct binding assays identified 81 additional mRNAs - perhaps mRNAs that are more likely to be associated with the in vivo FMRP mRNP complex ${ }^{50}$. These RNAs and their encoded proteins have diverse physiological functions, including involvement in cytoskeleton structure and function, synaptic transmission, peroxisomal biogenesis, membrane docking and fusion, nuclear transport and molecular chaperone-like activity. Several of the identified genes were near loci that have been linked to autism, a syndrome that is associated with fragile X syndrome, and another encodes the glucocorticoid receptor, which could be involved in the delayed return of glucocorticoids towards baseline after stress that is seen in individuals with fragile $\mathrm{X}$ syndrome ${ }^{83}$. These $81 \mathrm{mRNAs}$ show little overlap with those identified in previous studies, in part because there was little overlap in the sequences on the different array platforms; of those that did overlap with the array used by Brown et al. ${ }^{78}$, about $50 \%$ were identified using APRA, and some of them (23\%) contained the G-quartet structure ${ }^{78,79,82,84}$. Some of these mRNAs also showed upregulation, downregulation or differential localization of the mRNA or encoded protein in FMR1-knockout cells, which supports the idea that FMRP can function as either a translational repressor or activator, depending on the situation.

FMRP can also recognize mRNAs by associating with the small dendritic non-coding RNA BC1, which anneals to complementary regions of some mRNA targets, and could thereby recruit FMRP to specific mRNAs ${ }^{43}$ (FIG. 2c). In particular, BC1 RNA is predicted to base-pair to neuronal mRNAs that encode molecules that are important for synaptic structure and function (including MAP1B mRNA). BC1 RNA is predicted to have a stable secondary structure that includes two stem loops ${ }^{85}$. FMRP target mRNAs have sequence complementarity with the longer stem loop of $\mathrm{BC} 1$. A recent study showed that FMRP has all the properties of a potent nucleic acid chaperone in vitro - it promotes the annealing of nucleic acids with complementary sequences and strand exchange in a duplex nucleic acid structure $^{86}$, raising the possibility that FMRP has a direct role in $\mathrm{BC} 1 / \mathrm{mRNA}$ annealing. Further in vivo studies could elucidate whether BC1, mRNAs and FMRP can form a translational inhibition complex.

Another potential mechanism for FMRP-mediated translational control is based on its interaction with miRNAs. It has recently been shown that human FMRP associates with miRNAs, which inhibit mRNA expression $^{44}$. FMRP could contribute to this regulatory pathway by stabilizing the specific annealing between 
miRNAs and the complementary region in the $3^{\prime}$ UTR of the target mRNAs (FIG. 2d). miRNAs associated with the D. melanogaster homologue of FMRP have been cloned and their mRNA targets have been isolated ${ }^{87,88}$, but studies in mammals are still ongoing.

In summary, many candidate FMRP-interacting mRNAs and proteins have been identified, and further studies are now needed to characterize the specificity of these interactions. We believe that it is important to discuss these interactions in the context of our current knowledge of the properties of the RNA-binding domains found in FMRP, because they determine how FMRP binds its RNA targets (BOX 1).

\section{The role of FMRP in translation}

It has been proposed that FMRP is involved in the translational regulation of gene expression in neurons, and probably in the testes. mRNA translation can be regulated at various stages. In general, mechanisms that regulate translation include inhibition of translation initiation, blocking translation at the $48 \mathrm{~S}$ complex stage and inhibition of elongation ${ }^{89}$.

mRNA-specific inhibition at the elongation stage, which is also known as 'stalling ribosomes', has been described in mechanistic detail in only one case - in lower eukaryotes ${ }^{90}$. The various stages of translation can be distinguished by the size of the mRNP complex: non-translated mRNPs and translation-initiation complexes are all smaller than a ribosome (80S), whereas translated mRNPs contain at least one ribosome and are, therefore, heavier than $80 \mathrm{~S}$. Furthermore, some forms of non-translated mRNP tend to aggregate. The aggregates vary in size, but tend to be bigger still than translating polyribosomes. Examples include stress granules, which contain stalled $48 \mathrm{~S}$-initiation complexes $^{91}$, and neuronal mRNA transport granules, which contain inactive polysomes ${ }^{92}$ or granules that seem to lack ribosomes ${ }^{93}$.

Because FMRP is probably involved in translation, the distribution of FMRP-containing complexes on sucrose gradients has attracted considerable interest. Unfortunately, the results of such experiments have differed, depending on important methodological details. Initial studies found that, in mammalian cells, FMRP co-sedimented with actively translating polyribosomes ${ }^{94}$, whereas a different study found that FMRP co-fractionates with the mRNP fraction, which contains non-translated mRNPs and translationinitiation complexes ${ }^{62}$. Later, Warren and colleagues showed that FMRP is equally distributed between polysomes and $\mathrm{mRNPs}^{28,78}$. In D. melanogaster, FMRP associates with the $80 \mathrm{~S}$ and ribonucleoprotein fractions of the gradient ${ }^{88}$. Finally, Zalfa et al. reported that, in brain extracts, a large amount of FMRP co-sedimended with the mRNP fraction ${ }^{43}$. These discrepancies could be caused by differences in the extract preparation procedure or the cell lines used, or by differences in the ages of the animals from which the cells were taken. For example, Stefani et al. ${ }^{95}$ showed differences in the distribution of FMRP on sucrose gradients between young mice ( 9 days) and adult mice ( 5 months).
As putative FMRP target mRNAs are both up- and downregulated ${ }^{50}$, FMRP could both activate and repress translation. FMRP could shift between these roles during development and/or in different parts of the brain, or, perhaps more likely, it could serve as a repressor until activated by phosphorylation and/or other signalling mechanisms. Indeed, recent work in Hela cells has shown that, in the presence of sodium azide, FMRP can move between polysomes and stalling ribosomes according to its phoshorylation status ${ }^{96}$. A significant portion of brain FMRP assembles in RNP granules - visible as a peak on sucrose gradients that is even larger than that seen for polysomes ${ }^{97}$. The presence of FMRP in a granular form co-sedimenting with light mRNPs, ribosomes, polysomes and heavy mRNPs might reflect the existence of more than one FMRP complex, possibly associated with different FMRP functions such as transport, inibition and/or activation of translation.

\section{Structural and functional abnormalities}

Spine abnormalities. Various types of dendritic spine dysmorphogenesis associated with mental retardation have been detailed since the original descriptions appeared 30 years ago ${ }^{98,99}$. In patients with fragile X syndrome, spines are commonly longer and thinner than in control subjects ${ }^{3,5,100,101}$. Furthermore, patients with fragile $\mathrm{X}$ syndrome have more spines per unit length of dendrite ${ }^{5}$. Both the spine shape and spine density phenotypes are seen in FMR1-knockout mice $^{4,102}$. So far, a maximum of six brains from patients with fragile $\mathrm{X}$ syndrome have been studied for various brain areas, and the detailed family histories are not known for each patient, so other brain pathologies cannot be excluded. Nevertheless, all studies showed an excess of long, thin spines that resembled immature spines $^{3,5}$.

FMR1 is highly conserved between humans and mice, with nucleotide and amino acid identities of $95 \%$ and $97 \%$, respectively ${ }^{42}$. FMR1-knockout mice, strain C57/BL6, were generated by homologous recombination to disrupt exon 5. Normal FMRP protein is absent in this murine model of fragile $\mathrm{X}$ syndrome, which shows macroorchidism, deficits in spatial learning, hyperactivity ${ }^{103}$ and dendritic spine abnormalities (see below). With these features, FMR1-knockout mice are at least phenotypically a fair model of fragile X syndrome.

Although results from an animal model must be interpreted with caution, data from knockout mice ${ }^{103}$ have corroborated and expanded on the findings from patients. The mice have abnormal spines in the visual cortex, the barrel region of the somatosensory cortex and in cultured hippocampal neurons ${ }^{4-6,102,104}$. These spine abnormalities were reported to diminish in the somatosensory barrel cortex during development ${ }^{6}$, but recent research indicates that the abnormalities reemerge as the mice mature ${ }^{105}$ (L. Restivo, M. AmmassariTeule and C.B., unpublished observations). The excess of long, thin, immature-looking spines indicates that a pruning process that would normally eliminate excess spines during development, and that contributes to the 


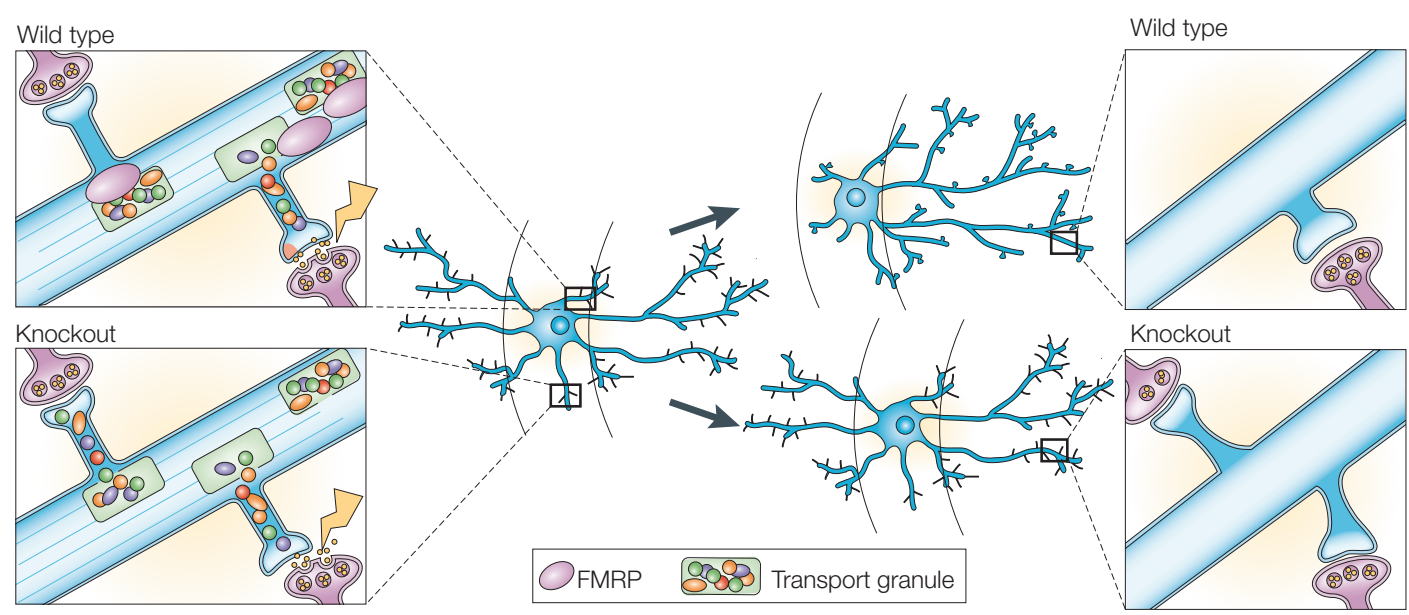

Figure 3 | How might an absence of FMRP lead to a failure to prune synapses? The figure shows a hypothetical mechanism through which the absence of fragile X mental retardation protein (FMRP) could lead to failure of synapse pruning and, as a consequence, dendrite pruning, in a typical spiny stellate neuron in a whisker barrel (centre). The model assumes that FMRP regulates the synthesis of structural proteins (for example, postsynaptic density protein 95 (PSD-95)) or signalling proteins that form part of a complex that is important for stabilizing and maturing developing synapses (see FIG. 4 for one possible conceptualization of this process). When FMRP is present, this stabilization complex (carried by the transport granule) is selectively targeted to active synapses (upper left), which results in selective maturation and stabilization of spines (upper right) and pruning of non-stabilized synapses. In the absence of FMRP (lower left), the stabilization complex is equally targeted to active and inactive synapses, which results in a weaker form of maturation and stabilization, and gives rise to greater numbers of synapses and an immature morphology (lower right).

development of brain circuitry ${ }^{106,107}$, might fail in these mice ${ }^{106,108}$. In a region of the somatosensory whisker barrel cortex where dendrites are normally withdrawn during development, the improperly located dendrites are not withdrawn in FMR1-knockout mice, and diminishing spine density parallels development of the spine shape phenotype from postnatal week 4 to adulthood $^{105,108}$. Combined with additional evidence ${ }^{102}$, this supports the view that the neuromorphological abnormalities that are seen in both fragile X syndrome and the mouse model involve, at least in part, a failure to prune synapses and parts of dendrites that would normally be eliminated during development.

If this is the case, then a reduction in FMRP must lead to an increased number of immature-looking synapses ${ }^{4,5,108}$. One way in which this could arise is if, in the absence of FMRP, newly formed synapses are stabilized (protected against loss), as in normal development, but the message or events that destabilize and lead to the removal of inappropriately positioned or inactive synapses do not occur. Of course, the normal destabilizing process could result simply from the absence of stabilizing events. One way in which such a process could yield the morphological results reported for spines and dendrites is illustrated in FIG. 3. If the stabilization of spines, and consequently dendrites, occurs because afferent activity regulates FMRPdependent, directed transport of crucial molecular elements of the stabilization process - the mRNA for a hypothetical 'stabilization protein' - this could lead to an absence of the stabilization protein at inactive synapses and, consequently, their loss, or pruning, in healthy humans and wild-type mice (FIG. 3, upper left panel). In the absence of FMRP in patients with fragile $\mathrm{X}$ syndrome or the mouse model, the stabilization protein would not be directed selectively to active synapses or dendrites and so all synapses in all dendrites would share equally in its effects (FIG. 3, lower left panel). In this case, activity-dependent pruning would not occur, or would not be selectively apparent in a particular region of the dendrite ${ }^{108}$ (FIG. 3, lower panels). This line of thinking is supported by reports that the FMRP-mRNA transport granules are actively (and bidirectionally) transported and that their transport from the soma into processes and spines is driven by neuronal activity ${ }^{49,54}$.

Environmental effects and plasticity. FMR1-knockout mice show abnormalities in behaviour and neuronal morphology that resemble those described in patients with fragile X syndrome ${ }^{7}$ (FIG. 4b,c). The importance of environment in the regulation of the brain, behaviour and physiology has long been recognized. ENVIRONMENTAL ENRICHMENT has been used extensively to show behavioural and brain plasticity in response to experience ${ }^{109,110}$. Rearing animals in a complex environment reduces anxiety ${ }^{111}$, accelerates habituation ${ }^{112}$, enhances learning ${ }^{113,114}$ and deeply affects brain morphology. In particular, rodents reared in enriched environments show increases in dendritic length and branching ${ }^{115}$, spine density, and the number, size and structure of synapses ${ }^{116,117}$.

Recent research indicates that environmental enrichment can largely rescue the behavioural and neuronal abnormalities in FMR1-knockout mice (L. Restivo, M. Ammassari-Teule and C.B., unpublished observations). In mice, FMRP is found in dendrites and spines ${ }^{28,49}$ and is regulated by activity: FMRP levels in the barrel cortex increase after stimulation, and levels in the cortex and hippocampus also increase when 

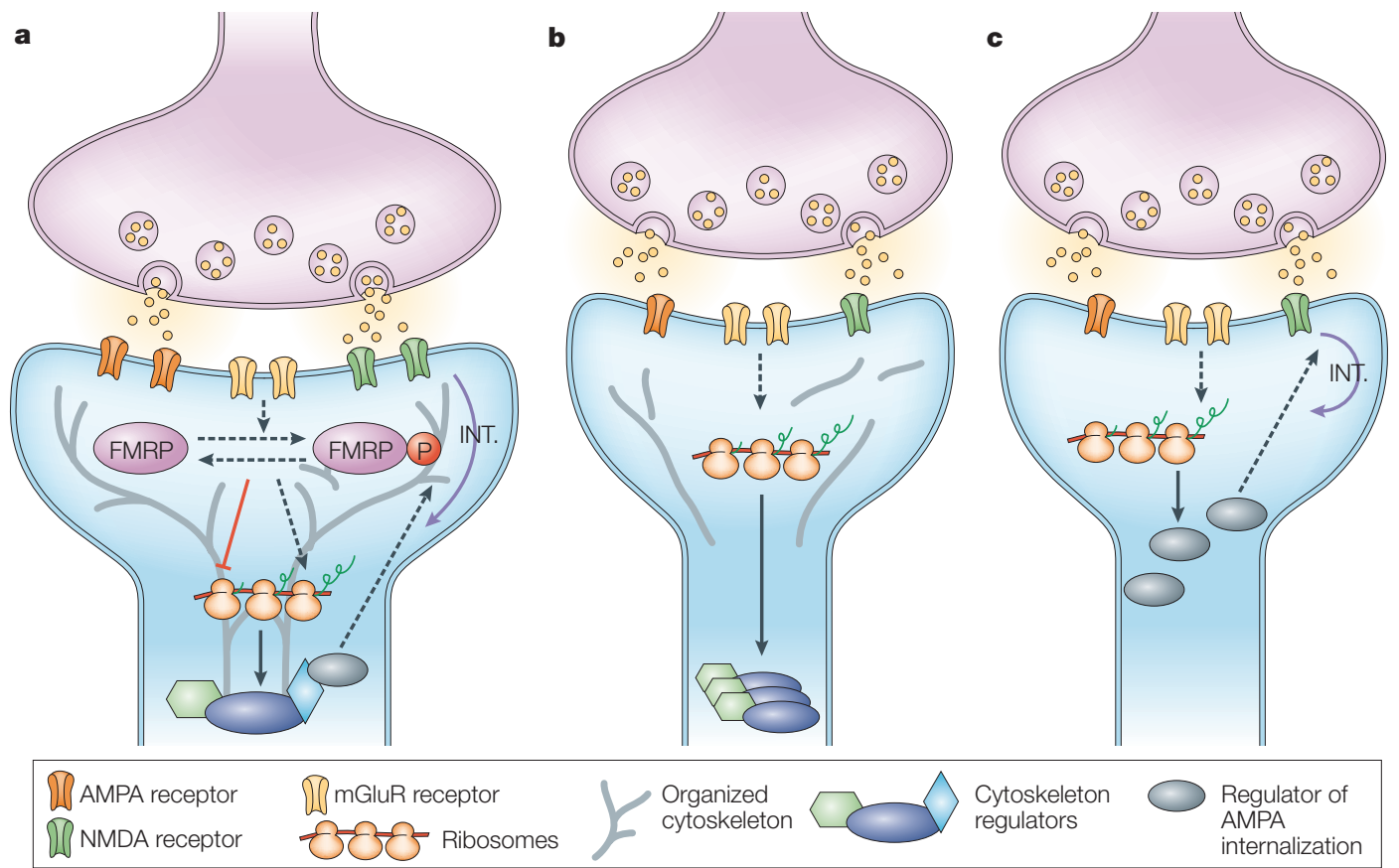

Cytoskeleton
regulators

Regulator of AMPA internalization

Figure 4 | A working model of FMRP at synapses. At synapses, protein synthesis is initiated by different cellular stimuli, and this leads to an independent response of a single synapse that can influence synaptic plasticity. a | In a wild-type spine, stimulation of metabotropic glutamate receptors enhances the synthesis of fragile $X$ mental retardation protein (FMRP), which could act to negatively regulate the translation of proteins that are involved in ionotropic receptor internalization during long-term depression and of proteins that regulate the cytoskeleton (such as microtubule-associated protein 1B (MAP1B), activity-regulated cytoskeletal-associated protein (ARC), arginine-binding protein 2 (ARGBP2), postsynaptic density protein 95 (PSD-95) and Rac1). This receptor-coupled signalling pathway might also be responsible for FMRP phosphorylation and the consequent release of mRNAs from translational inhibition and/or the activation of translation of other specific dendritic mRNAs. The correct balance between synthesis and degradation of these proteins would promote and maintain the mature shape of the synapse. $\mathbf{b} \mid$ In a spine of a patient with fragile X syndrome, or in the mouse model of the syndrome, the absence of FMRP would lead to an increase and/ or decrease in the translation of protein regulators of the cytoskeleton, both of which might have an effect on the lengthening of dendritic spines. c | The absence of FMRP could also lead to an increase in the translation of proteins that are involved in ionotropic (AMPA ( $\alpha$-amino-3-hydroxy-5-methyl-4-isoxazole propionic acid) and NMDA ( $N$-methyl-D-aspartate)) receptor internalization (INT.) during hippocampal long-term depression, which could lead to fewer receptors being present on the postsynaptic membrane and to thinner spines. mGluR, metabotropic glutamate receptor.

mice are reared in complex environments. Both of these areas are important for learning and memory $y^{118,119}$. FMR1 mRNA is present in synaptoneurosomes, and the synaptic level of FMRP increases after the administration of mGluR1-specific agonists ${ }^{24}$. In addition, FMRP regulates local mRNA translation, which could be a regulatory step in long-term plasticity (FIG. 4a), using the

\section{Box 2 | Synaptic plasticity}

Synaptic plasticity - indeed, the ability to change the synaptic structure - is thought to be involved in learning and memory, which are impaired in patients with fragile $\mathrm{X}$ syndrome. There are two main in vitro models for the study of synaptic plasticity: electrophysiological long-term potentiation (LTP) and long-term depression (LTD). An important contribution to both effects comes from the glutamatergic receptor system. Its receptors fall into two general classes: the ionotropic and the metabotropic receptors. The ionotropic AMPA ( $\alpha$-amino-3-hydroxy-5-methyl-4-isoxazole propionic acid) and NMDA ( $N$-methyl-D-aspartate) receptors at glutamatergic synapses are heteromeric complexes of homologous subunits (GluR1-4 for AMPA receptors, and NR1 and NR2A-D for NMDA receptors) that differentially combine to form various receptor subtypes ${ }^{150}$. Metabotropic glutamate receptors (mGluRs) consist of eight different members that can be subdivided into three groups on the basis of sequence homologies and their ability to couple to specific enzyme systems. same, overlapping or separate mechanisms from those involved in developmental synapse selection and modification. Activity-dependent potentiation of synaptic transmission is expressed through several parallel mechanisms and usually requires the synthesis of new proteins. Protein synthesis is thought to be an important component of many forms of long-term synaptic plasticity, and all of the components that are required for protein synthesis are found at synapses. This might allow neurons to translate new proteins precisely where, and only when, they are needed to modify synapses in response to potentiating stimuli or behavioural learning ${ }^{11}$. In hippocampal slices from developing rats, polyribosomes redistribute from dendritic shafts into spines with enlarged synapses during long-term potentiation (LTP) $)^{120}$ (BOX 2). Moreover, after stimulation or environmental enrichment, synapses are larger and more commonly contain polyribosomes ${ }^{25,117,121,122}$. This indicates that stimulation of synapses coincides with their enlargement, which accommodates local protein synthesis machinery. So, local protein synthesis seems to be an important component of synaptic plasticity. 
Hippocampal and cortical LTP. Possibly reflecting their poor performance in some types of memory and learning, FMR1-knockout mice show altered synaptic plasticity in brain areas involved in learning. In particular, they show reduced LTP in the cortex and enhanced mGluR-dependent long-term depression (LTD) in the hippocampus ${ }^{123,124}$ (BOX 2). mGluRdependent LTD depends on postsynaptic protein synthesis and involves the internalization of AMPA ( $\alpha$-amino-3-hydroxy-5-methyl-4-isoxazole propionic acid) and NMDA ( $N$-methyl-D-aspartate) receptors ${ }^{125}$. It has been proposed that FMRP might negatively regulate mRNAs that encode proteins involved in mGluR-dependent hippocampal LTD ${ }^{123}$. According to this model, FMRP, the glutamatergic system and synaptic plasticity could be linked together, possibly by mGluR-activated signalling pathways or a local increase in calcium from internal stores, which could ultimately alter the structure of dendritic spines ${ }^{126}$ (FIG. 4c). Some evidence predicts downregulation of mGluR1s in FMR1-knockout mice ${ }^{127}$. Interestingly, the knockout mice show no impairments in hippocampal LTP $^{128}$. Differential regulation of several mGluRs across age and brain regions could eventually explain this result.

\section{Perspectives and open questions}

mRNA export, localization and translation are important mechanisms for neuronal gene modulation. Some of these processes have been studied in considerable detail in different systems, and their mechanisms show some similarities. Although FMRP seems to have several roles in neurons, its precise place in the mechanisms of mRNA export, localization and translation remains to be defined. In particular, the specific RNA and protein partners of FMRP still need to be analysed in a frame that regards the cell as a dynamic entity in time and space. We leave the reader with several open questions, such as: does FMRP have a role, other than mRNA export, in the nucleus? Can FMRP interfere with or promote translational initiation, elongation and termination? Does FMRP have different partners at different stages of neuronal development? What proteins are involved in the modification and regulation of FMRP? Can the fragile X phenotype be improved by environmental alterations, and how does this compare with therapeutic behavioural intervention in patients? Future studies aimed at answering these questions will shed light on the mechanisms of mRNA export, localization and translation in the brain as well as in fragile $\mathrm{X}$ syndrome.
1. Oberle, I. et al. Instability of a 550-base pair DNA segment and abnormal methylation in fragile $X$ syndrome. Science 252, 1097-1102 (1991).

2. Hagerman, P. J. \& Hagerman, R. J. Fragile X-associated tremor/ataxia syndrome (FXTAS). Ment. Retard. Dev. Disabil. Res. Rev. 10, 25-30 (2004).

3. Hinton, V. J., Brown, W. T., Wisniewski, K. \& Rudelli, R. D. Analysis of neocortex in three males with the fragile $X$ syndrome. Am. J. Med. Genet. 41, 289-294 (1991).

4. Comery, T. A. et al. Abnormal dendritic spines in fragile $X$ knockout mice: maturation and pruning deficits. Proc. Natl Acad. Sci. USA 94, 5401-5404 (1997).

5. Irwin, S. A. et al. Abnormal dendritic spine characteristics in the temporal and visual cortices of patients with fragile- $X$ syndrome: a quantitative examination. Am. J. Med. Genet. 98, 161-167 (2001).

Provides the most thorough and the only quantitative description of the human fragile $\mathbf{X}$ cortical neuronal morphological phenotype.

6. Nimchinsky, E. A., Oberlander, A. M. \& Svoboda, K. Abnormal development of dendritic spines in FMR1 knockout mice. J. Neurosci. 21, 5139-5146 (2001).

7. Greenough, W. T. et al. Synaptic regulation of protein synthesis and the fragile X protein. Proc. Natl Acad. Sci. USA 98, 7101-7106 (2001).

8. Coss, R. G. \& Perkel, D. H. The function of dendritic spines: a review of theoretical issues. Behav. Neural Biol. 44, 151-185 (1985).

9. Nimchinsky, E. A. Sabatini, B. L. \& Svoboda, K. Structure and function of dendritic spines. Annu. Rev. Physiol. 64 313-353 (2002)

10. Campbell, D. S. \& Holt, C. E. Chemotropic responses of retinal growth cones mediated by rapid local protein synthesis and degradation. Neuron 32, 1013-1026 (2001).

11. Steward, O. \& Schuman, E. M. Compartmentalized synthesis and degradation of proteins in neurons. Neuron 40, 347-359 (2003).

12. Van de Bor, V. \& Davis, I. mRNA localisation gets more complex. Curr. Opin. Cell Biol. 16, 300-307 (2004).

13. Farina, K. L. \& Singer, R. H. The nuclear connection in RNA transport and localization. Trends Cell Biol. 12, 466-472 (2002).

14. Gu, W., Pan, F., Zhang, H., Bassell, G. J. \& Singer, R. H. A predominantly nuclear protein affecting cytoplasmic localization of $\beta$-actin mRNA in fibroblasts and neurons. J. Cell Biol. 156, 41-51 (2002).

15. Ainger, K. et al. Transport and localization elements in myelin basic protein mRNA. J. Cell Biol. 138, 1077-1087 (1997).
16. Shan, J., Munro, T. P., Barbarese, E., Carson, J. H. \& Smith, R. A molecular mechanism for mRNA trafficking in neuronal dendrites. J. Neurosci. 23, 8859-8866 (2003).

17. Deshler, J. O., Highett, M. I. \& Schnapp, B. J. Localization of Xenopus Vg1 mRNA by Vera protein and the endoplasmic reticulum. Science 276, 1128-1131 (1997).

18. Ross, A. F., Oleynikov, Y., Kislauskis, E. H., Taneja, K. L. \& Singer, R. H. Characterization of a $\beta$-actin mRNA zipcodebinding protein. Mol. Cell Biol. 17, 2158-2165 (1997).

19. Tiruchinapalli, D. M. et al. Activity-dependent trafficking and dynamic localization of zipcode binding protein 1 and $\beta$-actin mRNA in dendrites and spines of hippocampal neurons. J. Neurosci. 23, 3251-3261 (2003)

20. Kislauskis, E. H., Zhu, X. \& Singer, R. H. Sequences responsible for intracellular localization of $\beta$-actin messenger RNA also affect cell phenotype. J. Cell Biol. 127, 441-451 (1994).

21. Palacios, I. M., Gatfield, D., St Johnston, D. \& Izaurralde, E. An elF4Alll-containing complex required for mRNA localization and nonsense-mediated mRNA decay. Nature 427, 753-757 (2004).

Shows that the translation-initiation factor elF4AIII is a component of the oskar mRNP localization complex in $D$. melanogaster. Moreover, the same factor is also involved in nonsense-mediated mRNA decay in mammals.

22. Singh, G. \& Lykke-Andersen, J. New insights into the formation of active nonsense-mediated decay complexes. Trends Biochem. Sci. 28, 464-466 (2003).

23. Holbrook, J. A., Neu-Yilik, G., Hentze, M. W. \& Kulozik, A. E. Nonsense-mediated decay approaches the clinic. Nature Genet. 36, 801-808 (2004).

24. Weiler, I. J. et al. Fragile X mental retardation protein is translated near synapses in response to neurotransmitter activation. Proc. Natl Acad. Sci. USA 94, 5395-5400 (1997). Initial description of neurotransmitter activation of FMRP synthesis at the synapse (see also reference 25).

25. Weiler, I. J. et al. From the cover: fragile X mental retardation protein is necessary for neurotransmitter-activated protein translation at synapses. Proc. Natl Acad. Sci. USA 101 17504-17509 (2004).

26. Verheii, C. et al. Characterization and localization of the FMR-1 gene product associated with fragile $X$ syndrome. Nature 363, 722-724 (1993).

27. Eberhart, D. E., Malter, H. E., Feng, Y. \& Warren, S. T. The fragile $X$ mental retardation protein is a ribonucleoprotein containing both nuclear localization and nuclear export signals. Hum. Mol. Genet. 5, 1083-1091 (1996). An initial, detailed characterization of FMRP.
28. Feng, Y. et al. Fragile $\mathrm{X}$ mental retardation protein: nucleocytoplasmic shuttling and association with somatodendritic ribosomes. J. Neurosci. 17, 1539-1547 (1997).

29. Khandjian, E. W. et al. Novel isoforms of the fragile $X$ related protein FXR1P are expressed during myogenesis. Hum. Mol. Genet. 7, 2121-2128 (1998).

30. Ceman, S., Brown, V. \& Warren, S. T. Isolation of an FMRP-associated messenger ribonucleoprotein particle and identification of nucleolin and the fragile X-related proteins as components of the complex. Mol. Cell Biol. 19, 7925-7932 (1999).

31. Bardoni, B. et al. NUFIP1 (nuclear FMRP interacting protein 1) is a nucleocytoplasmic shuttling protein associated with active synaptoneurosomes. Exp. Cell Res. 289, 95-107 (2003).

32. Ceman, S., Nelson, R. \& Warren, S. T. Identification of mouse YB1/p50 as a component of the FMRP. associated mRNP particle. Biochem. Biophys. Res. Commun. 279, 904-908 (2000)

33. Stickeler, E. et al. The RNA binding protein YB-1 binds A/C-rich exon enhancers and stimulates splicing of the CD44 alternative exon v4. EMBO J. 20, 3821-3830 (2001).

34. Nekrasov, M. P. et al. The mRNA-binding protein YB-1 (p50) prevents association of the eukaryotic initiation factor elF4G with mRNA and inhibits protein synthesis at the initiation stage. J. Biol. Chem. 278, 13936-13943 (2003).

35. Sittler, A., Devys, D., Weber, C. \& Mandel, J. L. Alternative splicing of exon 14 determines nuclear or cytoplasmic localisation of fmr1 protein isoforms. Hum. Mol. Genet. 5, 95-102 (1996).

36. De Boulle, K. et al. A point mutation in the FMR-1 gene associated with fragile $\mathrm{X}$ mental retardation. Nature Genet. 3, 31-35 (1993)

37. Tamanini, F. et al. Different targets for the fragile X-related proteins revealed by their distinct nuclear localizations. Hum. Mol. Genet. 8, 863-869 (1999).

38. Nakamura, M. et al. When overexpressed, a nove centrosomal protein, RanBPM, causes ectopic microtubule nucleation similar to $\gamma$-tubulin. J. Cell Biol. 143, 1041-1052 (1998).

39. Menon, R. P., Gibson, T. J. \& Pastore, A. The $\mathrm{C}$ terminus of fragile $\mathrm{X}$ mental retardation protein interacts with the multi-domain Ran-binding protein in the microtubule-organising centre. J. Mol. Biol. 343, 43-53 (2004).

40. Hoelz, A. \& Blobel, G. Cell biology: popping out of the nucleus. Nature 432, 815-816 (2004). 
41. Greenbaum, L., Katcoff, D. J., Dou, H., Gozlan, Y. \& Malik, Z. A porphobilinogen deaminase (PBGD) Ranbinding protein interaction is implicated in nuclear trafficking of PBGD in differentiating glioma cells. Oncogene 22, 5221-5228 (2003).

42. Ashley, C. T. et al. Human and murine FMR-1: alternative splicing and translational initiation downstream of the CGG-repeat. Nature Genet. 4, 244-251 (1993).

43. Zalfa, F. et al. The fragile X syndrome protein FMRP associates with $\mathrm{BC} 1 \mathrm{RNA}$ and regulates the translation of specific mRNAs at synapses. Cell 112, 317-327 (2003).

This work reveals an intriguing mechanism by which FMRP regulates the translation of some neuronal mRNAs at synapses through the small non-coding RNA BC1. This RNA functions as an 'adaptor molecule' between FMRP and its mRNA targets. The FMRP-mRNA target interaction can be inhibited using a chemically synthesized oligo against BC1 RNA.

44. Jin, P. et al. Biochemical and genetic interaction between the fragile $X$ mental retardation protein and the microRNA pathway. Nature Neurosci. 7, 113-117 (2004).

45. He, L. \& Hannon, G. J. MicroRNAs: small RNAs with a big role in gene regulation. Nature Rev. Genet. 5, 522-531 (2004).

46. Jenuwein, T. Molecular biology. An RNA-guided pathway for the epigenome. Science 297, 2215-2218 (2002).

47. Bao, N., Lye, K. W. \& Barton, M. K. MicroRNA binding sites in Arabidopsis class III HD-ZIP mRNAs are required for methylation of the template chromosome. Dev. Cell 7 , 653-662 (2004)

48. Matzke, M. A. \& Birchler, J. A. RNAi-mediated pathways in the nucleus. Nature Rev. Genet. 6, 24-35 (2005)

49. Antar, L. N., Afroz, R., Dictenberg, J. B., Carroll, R. C. \& Bassell, G. J. Metabotropic glutamate receptor activation regulates fragile $\mathrm{X}$ mental retardation protein and $\mathrm{Fmr} 1$ mRNA localization differentially in dendrites and at synapses. J. Neurosci. 24, 2648-2655 (2004). Shows clearly, for the first time, evidence of activitydependent regulation of FMRP and FMR1 mRNA trafficking in dendrites and synapses. In particular, the authors show that synaptic activation through the mGluR5 receptor regulates the localization of FMRP and FMR1 mRNA in dendrites.

50. Miyashiro, K. Y. et al. RNA cargoes associating with FMRP reveal deficits in cellular functioning in Fmr1 null mice. Neuron 37, 417-431 (2003).

51. Steward, O., Bakker, C. E., Willems, P. J. \& Oostra, B. A No evidence for disruption of normal patterns of mRNA localization in dendrites or dendritic transport of recently synthesized mRNA in FMR1 knockout mice, a model for human fragile-X mental retardation syndrome. Neuroreport 9, 477-481 (1998)

52. Kanai, Y., Dohmae, N. \& Hirokawa, N. Kinesin transports RNA: isolation and characterization of an RNA-transporting granule. Neuron 43, 513-525 (2004).

A thorough description and functional assessment of the composition of granules that contain FMRP and transport its mRNAs (see also references 49,60 ). They identified more than $\mathbf{4 0}$ proteins including Staufen, FMRP and other factors involved in protein synthesis In addition, they showed the presence of $\alpha$-CaMKII and ARC mRNAs in these granules.

53. Rackham, O. \& Brown, C. M. Visualization of RNA-protein interactions in living cells: FMRP and IMP1 interact on mRNAs. EMBO J. 23, 3346-3355 (2004).

54. Ling, S. C., Fahrner, P. S., Greenough, W. T. \& Gelfand, V. I. Transport of Drosophila fragile X mental retardation protein-containing ribonucleoprotein granules by kinesin-1 and cytoplasmic dynein. Proc. Natl Acad. Sci. USA 101, 17428-17433 (2004)

55. Schrier, M. et al. Transport kinetics of FMRP containing the I304N mutation of severe fragile $X$ syndrome in neurites of living rat PC12 cells. Exp. Neurol. 189, 343-353 (2004).

56. Clarke, N. F., Mowat, D., Kooy, R. F., Reyniers, E. \& Willemsen, R. Fragile X syndrome phenotype with normal FMR1 gene studies. Am. J. Med. Genet. 129, 326-328 (2004).

57. Zhang, Y. et al. The fragile X mental retardation syndrome protein interacts with novel homologs FXR1 and FXR2 EMBO J. 14, 5358-5366 (1995).

58. Schenck, A., Bardoni, B., Moro, A., Bagni, C. \& Mandel, J. L. A highly conserved protein family interacting with the fragile $X$ mental retardation protein (FMRP) and displaying selective interactions with FMRP-related proteins FXR1P and FXR2P. Proc. Natl Acad. Sci. USA 98, 8844-8849 (2001). The authors characterized two cytoplasmic FMRPinteracting proteins, both of which are also present at synapses.This work represents one of the first links between FMRP and the cytoskeleton (see also reference 68 ).
59. Bardoni, B. \& Mandel, J. L. Advances in understanding of fragile $X$ pathogenesis and FMRP function, and in identification of $X$ linked mental retardation genes. Curr. Opin. Genet. Dev. 12, 284-293 (2002).

60. Ohashi, S. et al. Identification of mRNA/protein (mRNP) complexes containing Pur $\alpha$, mStaufen, fragile $X$ protein, and myosin Va and their association with rough endoplasmic reticulum equipped with a kinesin motor. J. Biol. Chem. 277, 37804-37810 (2002).

Shows that a possible molecular machinery containing PUR $\alpha$, Staufen, myosin VA and FMRP might be involved in the regulatation of dendritic transport.

61. Villace, P., Marion, R. M. \& Ortin, J. The composition of Staufen-containing RNA granules from human cells indicates their role in the regulated transport and translation of messenger RNAs. Nucleic Acids Res. 32, 2411-2420 (2004).

62. Siomi, M. C., Zhang, Y., Siomi, H. \& Dreyfuss, G. Specific sequences in the fragile $X$ syndrome protein FMR1 and the FXR proteins mediate their binding to $60 S$ ribosomal subunits and the interactions among them. Mol. Cell Biol. 16, 3825-3832 (1996)

63. Adinolfi, S. et al. The $\mathrm{N}$-terminus of the fragile $\mathrm{X}$ mental retardation protein contains a novel domain involved in dimerization and RNA binding. Biochemistry 42 10437-10444 (2003).

64. Agulhon, C. et al. Expression of FMR1, FXR1, and FXR2 genes in human prenatal tissues. J. Neuropathol. Exp. Neurol. 58, 867-880 (1999).

65. Sreeram, N., Wren, C., Bhate, M., Robertson, P. \& Hunter, S. Cardiac abnormalities in the fragile X syndrome. Br. Heart $J$. 61, 289-291 (1989)

66. Mientjes, E. J. et al. Fxr1 knockout mice show a striated muscle phenotype: implications for Fxr1p function in vivo. Hum. Mol. Genet. 13, 1291-1302 (2004)

67. Kobayashi, K. et al. p140Sra-1 (specifically Rac1associated protein) is a novel specific target for Rac1 small GTPase. J. Biol. Chem. 273, 291-295 (1998).

68. Schenck, A. et al. CYFIP/Sra-1 controls neuronal connectivity in Drosophila and links the Rac1 GTPase pathway to the fragile X protein. Neuron $\mathbf{3 8}, 887-898$ (2003).

69. Bardoni, B. et al. 82-FIP, a novel FMRP (fragile X mental retardation protein) interacting protein, shows a cell cycledependent intracellular localization. Hum. Mol. Genet. 12 1689-1698 (2003)

70. Kohrmann, M. et al. Microtubule-dependent recruitment of Staufen-green fluorescent protein into large RNAcontaining granules and subsequent dendritic transport in living hippocampal neurons. Mol. Biol. Cell 10, 2945-2953 (1999).

71. Li, Y. et al. Pur $\alpha$ protein implicated in dendritic RNA transport interacts with ribosomes in neuronal cytoplasm. Biol. Pharm. Bull. 24, 231-235 (2001).

72. Duchaine, T. F. et al. Staufen2 isoforms localize to the somatodendritic domain of neurons and interact with different organelles. J. Cell Sci. 115, 3285-3295 (2002)

73. Ohashi, S. et al. The single-stranded DNA- and RNAbinding proteins pur $\alpha$ and pur $\beta$ link BC1 RNA to microtubules through binding to the dendrite-targeting RNA motifs. J. Neurochem. 75, 1781-1790 (2000).

74. Mallardo, M. et al. Isolation and characterization of Staufencontaining ribonucleoprotein particles from rat brain. Proc Natl Acad. Sci. USA 100, 2100-2105 (2003).

75. Pastural, E. et al. Two genes are responsible for Griscell syndrome at the same 15q21 locus. Genomics 63 , 299-306 (2000)

76. Siomi, M. C. et al. FXR1, an autosomal homolog of the fragile X mental retardation gene. EMBO J. 14, 2401-2408 (1995).

77. Adinolfi, S. et al. Dissecting FMR1, the protein responsible for fragile $X$ syndrome, in its structural and functional domains. RNA 5, 1248-1258 (1999).

78. Brown, V. et al. Microarray identification of FMRPassociated brain mRNAs and altered mRNA translational profiles in fragile X syndrome. Cell 107, 477-487 (2001)

79. Darnell, J. C. et al. Fragile X mental retardation protein targets $G$ quartet mRNAs important for neuronal function. Cell 107, 489-499 (2001).

Describes an approach to identifying mRNA 'cargoes' of FMRP (see also references 50,78,80)

80. Chen, L., Yun, S. W., Seto, J., Liu, W. \& Toth, M. The fragile $X$ mental retardation protein binds and regulates a novel class of mRNAs containing $U$ rich target sequences. Neuroscience 120, 1005-1017 (2003).

81. Zhang, Y. Q. et al. Drosophila fragile X-related gene regulates the MAP1B homolog futsch to control synaptic structure and function. Cell 107, 591-603 (2001).

82. Schaeffer, C. et al. The fragile $X$ mental retardation protein binds specifically to its mRNA via a purine quartet motif. EMBO J. 20, 4803-4813 (2001).
83. Hessl, D., Rivera, S. M. \& Reiss, A. L. The neuroanatomy and neuroendocrinology of fragile $X$ syndrome. Ment. Retard. Dev. Disabil. Res. Rev. 10, 17-24 (2004).

84. Ramos, A., Hollingworth, D. \& Pastore, A. G-quartetdependent recognition between the FMRP RGG box and RNA. RNA 9, 1198-1207 (2003).

85. Rozhdestvensky, T. S., Kopylov, A. M., Brosius, J. \& Huttenhofer, A. Neuronal BC1 RNA structure: evolutionary conversion of a tRNA(Ala) domain into an extended stem-loop structure. RNA 7, 722-730 (2001).

86. Gabus, C., Mazroui, R., Tremblay, S., Khandjian, E. W. \& Darlix, J. L. The fragile X mental retardation protein has nucleic acid chaperone properties. Nucleic Acids Res. 32, 2129-2137 (2004)

87. Caudy, A. A., Myers, M., Hannon, G. J. \& Hammond, S. M. Fragile X-related protein and VIG associate with the RNA interference machinery. Genes Dev. 16, 2491-2496 (2002).

This study provides the first evidence that the D. melanogaster FMRP is part of the RNAi-related machinery (see also reference 88 ).

88. Ishizuka, A., Siomi, M. C. \& Siomi, H. A Drosophila fragile X protein interacts with components of RNAi and ribosomal proteins. Genes Dev. 16, 2497-2508 (2002).

The authors of this study suggest a model in which the RNAi pathway and D. melanogaster FMRPmediated translational control intersect with each other (see also reference 86).

89. Gebauer, F. \& Hentze, M. W. Molecular mechanisms of translational control. Nature Rev. Mol. Cell Biol. 5 827-835 (2004)

90. Chapman, R. E. \& Walter, P. Translational attenuation mediated by an mRNA intron. Curr. Biol. 7, 850-859 (1997).

91. Kedersha, N. \& Anderson, P. Stress granules: sites of mRNA triage that regulate mRNA stability and translatability. Biochem. Soc. Trans. 30, 963-969 (2002).

92. Krichevsky, A. M. \& Kosik, K. S. Neuronal RNA granules: a link between RNA localization and stimulationdependent translation. Neuron 32, 683-696 (2001).

93. Antic, D. \& Keene, J. D. Messenger ribonucleoprotein complexes containing human ELAV proteins: interactions with cytoskeleton and translational apparatus. J. Cell Sci. 111, 183-197 (1998)

94. Khandjian, E. W., Corbin, F., Woerly, S. \& Rousseau, F. The fragile $X$ mental retardation protein is associated with ribosomes. Nature Genet. 12, 91-93 (1996).

95. Stefani, G., Fraser, C. E., Darnell, J. C. \& Darnell R. B. Fragile $\mathrm{X}$ mental retardation protein is associated with translating polyribosomes in neuronal cells. J. Neurosci. 24, $7272-7276$ (2004)

96. Ceman, S. et al. Phosphorylation influences the translation state of FMRP-associated polyribosomes. Hum. Mol. Genet. 12, 3295-3305 (2003).

97. Aschrafi, A., Cunningham, B. A., Edelman, G. M. \& Vanderklish, P. W. The fragile X mental retardation protein and group I metabotropic glutamate receptors regulate levels of mRNA granules in brain. Proc. Natl Acad. Sci. USA 102, 2180-2185 (2005).

98. Purpura, D. P. Dendritic spine 'dysgenesis' and mental retardation. Science 186, 1126-1128 (1974).

99. Marin-Padilla, M. Structural abnormalities of the cerebral cortex in human chromosomal aberrations: a Golgi study. Brain Res. 44, 625-629 (1972).

100. Wisniewski, K. E. et al. Fragile X syndrome: associated neurological abnormalities and developmental disabilities. Ann. Neurol. 18, 665-669 (1985).

101. Rudelli, R. D. et al. Adult fragile X syndrome. Cliniconeuropathologic findings. Acta Neuropathol. (Berl.) 67 289-295 (1985)

102. McKinney, B. C., Grossman, A. W., Elisseou, N. M. \& Greenough, W. T. Dendritic spine abnormalities in the occipital cortex of C57BL/6 Fmr1 knockout mice. Am. J. Med. Genet. (in the press).

103. Bakker, C. E. et al. Fmr1 knockout mice: a model to study fragile X mental retardation. Cell 78, 23-33 (1994).

104. Braun, K. \& Segal, M. FMRP involvement in formation of synapses among cultured hippocampal neurons. Cereb. Cortex 10, 1045-1052 (2000).

105. Galvez, R. \& Greenough, W. T. Sequence of abnormal dendritic spine development in primary somatosensory cortex of a mouse model of the fragile X mental retardation syndrome. Am. J. Med. Genet. (in the press).

106. Greenough, W. T. \& Chang, F. L. Dendritic pattern formation involves both oriented regression and oriented growth in the barrels of mouse somatosensory cortex. Brain Res. 471, 148-152 (1988).

107. Huttenlocher, P. R. \& Dabholkar, A. S. Regional differences in synaptogenesis in human cerebral cortex. J. Comp. Neurol. 387, 167-178 (1997). 
108. Galvez, R., Gopal, A. R. \& Greenough, W. T. Somatosensory cortical barrel dendritic abnormalities in a mouse model of the fragile $X$ mental retardation syndrome. Brain Res. 971, 83-89 (2003).

Evidence that synaptic pruning deficiencies give rise to the neuronal phenotype of fragile $X$ syndrome.

109. Volkmar, F. R. \& Greenough, W. T. Rearing complexity affects branching of dendrites in the visual cortex of the rat. Science 176, 1145-1147 (1972).

110. van Praag, H., Kempermann, G. \& Gage, F. H. Neural consequences of environmental enrichment. Nature Rev. Neurosci. 1, 191-198 (2000).

111. Benaroya-Milshtein, N. et al. Environmental enrichment in mice decreases anxiety, attenuates stress responses and enhances natural killer cell activity. Eur. J. Neurosci. 20, 1341-1347 (2004)

112. Schrijver, N. C., Bahr, N. I., Weiss, I. C. \& Wurbel, H. Dissociable effects of isolation rearing and environmental enrichment on exploration, spatial learning and HPA activity in adult rats. Pharmacol. Biochem. Behav. 73, 209-224 (2002).

113. Moser, M. B., Trommald, M., Egeland, T. \& Andersen, P. Spatial training in a complex environment and isolation alter the spine distribution differently in rat CA1 pyramidal cells. J. Comp. Neurol. 380, 373-381 (1997).

114. Lee, E. H., Hsu, W. L., Ma, Y. L., Lee, P. J. \& Chao, C. C. Enrichment enhances the expression of $s g k$, a glucocorticoid-induced gene, and facilitates spatial learning through glutamate AMPA receptor mediation. Eur. J. Neurosci. 18, 2842-2852 (2003).

115. Greenough, W. T., Yuwiler, A. \& Dollinger, M. Effects of posttrial eserine administration on learning in 'enriched'and 'impoverished'-reared rats. Behav. Biol. 8, 261-272 (1973).

116. Diamond, M. C. \& Connor, J. R. Jr. Plasticity of the aging cerebral cortex. Exp. Brain Res. 5 (suppl.), 36-44 (1982).

117. Turner, A. M. \& Greenough, W. T. Differential rearing effects on rat visual cortex synapses. I. Synaptic and neuronal density and synapses per neuron. Brain Res. 329, 195-203 (1985).

118. Irwin, S. A. et al. Evidence for altered Fragile-X mental retardation protein expression in response to behavioral stimulation. Neurobiol. Learn. Mem. 74, 87-93 (2000).

119. Todd, P. K. \& Mack, K. J. Sensory stimulation increases cortical expression of the fragile X mental retardation protein in vivo. Brain Res. Mol. Brain Res. 80, 17-25 (2000).

120. Ostroff, L. E., Fiala, J. C. Allwardt, B. \& Harris, K. M. Polyribosomes redistribute from dendritic shafts into spines with enlarged synapses during LTP in developing rat hippocampal slices. Neuron 35, 535-545 (2002). A landmark study on how dendritic protein synthesis might stabilize the growth of the postsynaptic density, including an increase in the number of ribosomes, after the induction of LTP by tetanic stimulation.

121. Chang, F. L. \& Greenough, W. T. Transient and enduring morphological correlates of synaptic activity and efficacy change in the rat hippocampal slice. Brain Res. 309, 35-46 (1984).

122. Greenough, W. T., Hwang, H. M. \& Gorman, C. Evidence for active synapse formation or altered postsynaptic metabolism in visual cortex of rats reared in complex environments. Proc. Natl Acad. Sci. USA 82, 4549-4552 (1985).

123. Huber, K. M., Gallagher, S. M., Warren, S. T. \& Bear, M. F. Altered synaptic plasticity in a mouse model of fragile $X$ mental retardation. Proc. Natl Acad. Sci. USA 99, 77467750 (2002).
124. Li, J., Pelletier, M. R., Perez Velazquez, J. L. \& Carlen, P. L. Reduced cortical synaptic plasticity and GluR1 expression associated with fragile $X$ mental retardation protein deficiency. Mol. Cell Neurosci. 19, 138-151 (2002).

125. Snyder, E. M. et al. Internalization of ionotropic glutamate receptors in response to mGluR activation. Nature Neurosci. 4, 1079-1085 (2001).

126. Vanderklish, P. W. \& Edelman, G. M. Dendritic spines elongate after stimulation of group 1 metabotropic glutamate receptors in cultured hippocampal neurons. Proc. Natl Acad. Sci. USA 99, 1639-1644 (2002).

127. Bear, M. F., Huber, K. M. \& Warren, S. T. The mGluR theory of fragile X mental retardation. Trends Neurosci. 27, 370-377 (2004).

128. Godfraind, J. M. et al. Long-term potentiation in the hippocampus of fragile X knockout mice. Am. J. Med. Genet. 64, 246-251 (1996). Initial evidence for a direct effect of FMR1 knockout on a widely studied model of learning and memory (see also reference 122).

129. Siomi, H., Siomi, M. C., Nussbaum, R. L. \& Dreyfuss, G. The protein product of the fragile X gene, FMR1, has characteristics of an RNA-binding protein. Cell 74, 291-298 (1993).

130. Adinolfi, S. et al. Novel RNA-binding motif: the $\mathrm{KH}$ module. Biopolymers 51, 153-164 (1999).

131. Gibson, T. J., Thompson, J. D. \& Heringa, J. The KH domain occurs in a diverse set of RNA-binding proteins that include the antiterminator NusA and is probably involved in binding to nucleic acid. FEBS Lett. 324, 361-366 (1993).

132. Lewis, H. A. et al. Sequence-specific RNA binding by a Nova KH domain: implications for paraneoplastic disease and the fragile X syndrome. Cell 100, 323-332 (2000).

133. Duncan, R. et al. A sequence-specific, single-strand binding protein activates the far upstream element of c-myc and defines a new DNA-binding motif. Genes Dev. 8 , 465-480 (1994)

134. Michelotti, E. F., Michelotti, G. A., Aronsohn, A. I. \& Levens, D. Heterogeneous nuclear ribonucleoprotein $\mathrm{K}$ is a transcription factor. Mol. Cell Biol. 16, 2350-2360 (1996).

135. Kiledjian, M. \& Dreyfuss, G. Primary structure and binding activity of the hnRNP $U$ protein: binding RNA through RGG box. EMBO J. 11, 2655-2664 (1992).

136. Zhang. S. \& Grosse, F. Domain structure of human nuclear DNA helicase II (RNA helicase A). J. Biol. Chem. 272. 11487-11494 (1997).

137. Sandri-Goldin, R. M. ICP27 mediates HSV RNA export by shuttling through a leucine-rich nuclear export signal and binding viral intronless RNAs through an RGG motif. Genes Dev. 12, 868-879 (1998)

138. Ghisolfi, L., Kharrat, A., Joseph, G., Amalric, F. \& Erard, M. Concerted activities of the RNA recognition and the glycinerich $\mathrm{C}$-terminal domains of nucleolin are required for efficient complex formation with pre-ribosomal RNA. Eur. J. Biochem. 209, 541-548 (1992).

139. Fouraux, M. A., Bouvet, P., Verkaart, S., van Venrooij, W. J. \& Pruijn, G. J. Nucleolin associates with a subset of the human Ro ribonucleoprotein complexes. J. Mol. Biol. 320 475-488 (2002)

140. Lapeyre, B. et al. Molecular cloning of Xenopus fibrillarin, a conserved U3 small nuclear ribonucleoprotein recognized by antisera from humans with autoimmune disease. Mol. Cell Biol. 10, 430-434 (1990).

141. Bagni, C. \& Lapeyre, B. Gar1p binds to the small nucleolar RNAs snR10 and snR30 in vitro through a nontypical RNA binding element. J. Biol. Chem. 273, 10868-10873 (1998).

142. Lee, W. C., Xue, Z. X. \& Melese, T. The NSR1 gene encodes a protein that specifically binds nuclear localization sequences and has two RNA recognition motifs. J. Cell Biol. 113, 1-12 (1991).
143. Nichols, R. C. et al. The RGG domain in hnRNP A2 affects subcellular localization. Exp. Cell Res. 256, 522-532 (2000).

144. Maurer-Stroh, S. et al. The Tudor domain 'Royal Family': Tudor, plant Agenet, Chromo, PWWP and MBT domains. Trends Biochem. Sci. 28, 69-74 (2003).

145. Siomi, H., Choi, M., Siomi, M. C., Nussbaum, R. L. \& Dreyfuss, G. Essential role for KH domains in RNA binding: impaired RNA binding by a mutation in the $\mathrm{KH}$ domain of FMR1 that causes fragile X syndrome. Cell 77, 33-39 (1994).

146. Feng, Y. et al. FMRP associates with polyribosomes as an mRNP, and the $1304 \mathrm{~N}$ mutation of severe fragile $X$ syndrome abolishes this association. Mol. Cell 1, 109-118 (1997).

147. Brown, V. et al. Purified recombinant Fmrp exhibits selective RNA binding as an intrinsic property of the fragile $X$ mental retardation protein. J. Biol. Chem. 273, 15521-15527 (1998).

148. Laggerbauer, B., Ostareck, D., Keidel, E. M., OstareckLederer, A. \& Fischer, U. Evidence that fragile X mental retardation protein is a negative regulator of translation. Hum. Mol. Genet. 10, 329-338 (2001).

149. Li, Z. et al. The fragile X mental retardation protein inhibits translation via interacting with mRNA. Nucleic Acids Res. 29, 2276-2283 (2001).

150. Hollmann, M. \& Heinemann, S. Cloned glutamate receptors. Annu. Rev. Neurosci. 17, 31-108 (1994).

151. Bardoni, B., Schenck, A. \& Mandel, J. L. A novel RNAbinding nuclear protein that interacts with the fragile $X$ mental retardation (FMR1) protein. Hum. Mol. Genet. 8, 2557-2566 (1999)

152. Brendel, C. et al. Characterization of Staufen 1 ribonucleoprotein complexes. Biochem. J. 384, 239-246 (2004).

\section{Acknowledgements}

We are grateful to T. Achsel, I. J. Weiler and F. Zalfa for critical reading of the manuscript and to $G$. Bernardi for his support. Work in C.B.'s group was supported by Telethon-Italy, Ministero dell'Istruzione, dell'Università e della Ricerca and Ministero della Salute. Work in W.G.'s laboratory was supported by the National Institute of Mental Health, the National Institute of Child Health and Human Developent and the Fragile X Research Foundation.

Competing interests statement

The authors declare no competing financial interests.

\section{(2)) Online links}

\section{DATABASES}

The following terms in this article are linked online to:

Entrez Gene: http://www.ncbi.nlm.nih.gov/entrez/query.

fcgi?db=gene

$\alpha$ CaMKII | ARC | CYFIP1 | CYFIP2 | DAG1 | elF2C2 | FMR1 |

IMP1 | MAP1B | MAP2 | NUFIP | PUR $\alpha$ | PURß | RanBPM | RGS5

$\mid \mathrm{YB} 1$

OMIM: http://www.ncbi.nlm.nih.gov/entrez/quer.

fcgi?db=OMIM

Fragile X syndrome | Griscelli syndrome

\section{FURTHER INFORMATION}

Bagni's laboratory: http://www.hpage.it/cb

Greenough's laboratory: http://greenough.beckman.uiuc.edu

Conquer Fragile X: http://www.conquerfragileX.org

The Fragile X Research Foundation: http://www.fraxa.org

The National Fragile X Foundation: http://www.FragileX.org

Sindrome X-Fragile: http://www.xfragile.ne

Access to this interactive links box is free online. 